\title{
O COMPORTAMENTO DA MAMONA NO NORDESTE BRASILEIRO: UMA ANÁLISE DAS FONTES DE CRESCIMENTO NO PERÍODO DE 1990 A 2016
}

\author{
Renan Silva Ferreira" \\ Andre Souza Melo**
}

RESUMO: Este trabalho tem como objetivo apresentar um panorama acerca da produção da mamona nordestina entre os anos de 1990 a 2016. A produção será identificada pelo valor bruto de produção, verificando em que nível as componentes variáveis: área colhida, produtividade média e preço influenciaram nas oscilações de crescimento. O método aplicado na pesquisa tem ênfase na discussão do Modelo Shift-Share, e os resultados são discutidos na sequência, o qual são importantes indicadores para envolver o planejamento da produção da cultura da mamona, onde se pode observar a grande influência da produção baiana, mas também uma grande adaptabilidade em outras regióes, detalhando-se o comportamento destas fases de produção ao longo dos anos estudados.

PALAVRAS-CHAVE: Mamona; Modelo Shift-Share; Valor Bruto da Produção.

\section{THE BEHAVIOR OF CASTOR BEAN IN THE NORTHEASTERN REGION OF BRAZIL: AN ANALYSIS OF GROWTH SOURCES IN THE 1990-2016 PERIOD}

\begin{abstract}
A survey on the production of castor beans in the northeastern region of Brazil between 1990 and 2016 is provided. Production is identified by gross production value, verifying the level of variables, such as harvest area, mean productivity and price, affecting prices through growth oscillations. The shift-share model was employed and results were discussed. They are relevant indicators for the planning of castor bean production, pinpointing the great influence of production in the state of Bahia and great adaptability in other regions, with details on the behavior of production phases over the years under analysis.
\end{abstract}

KEY WORDS: Castor bean; Shift-Share model; Gross production value.

\footnotetext{
Mestrando no Programa de Pós-graduação em Administração e Desenvolvimento Rural (PADR/UFRPE). Brasil. E-mail: renan.demolay_178@hotmail.com

** Doutor em Economia (UFPE). Docente da UFRPE e Coordenador/corpo docente do PADR (Mestrado) UFRPE. Brasil.
} 


\section{INTRODUÇÃO}

Os biocombustíveis assumem características vantajosas ambiental, econômica e socialmente, transcendendo ganhos de forma ecológica, tornando-a prática sustentável. E o processo de geração de energia é uma grande referência na história, e o Brasil é reconhecido como líder na produção de biocombustíveis de origem vegetal, e em termos de políticas públicas, planos como o Programa Nacional de Produção e Uso de Biodiesel (PNPB) e Selo de Combustível Social incentivam a inserção de pequenos agricultores na cadeia produtiva deste setor.

O Nordeste apresenta uma limitação de recursos naturais na agricultura, mas potencializa a diversidade de solo, vegetação e clima, principalmente para plantas oleaginosas significantes para produção industrial do biodiesel e para o aspecto alimentício - que apesar de intempéries climáticas que tornam as safras instáveis. Desta forma, segundo Melo (2016), avalia-se que o cultivo das matérias-primas participantes desta produção industrial eleva a empregabilidade além da variabilidade de fins, e o Brasil se configura como um dos maiores consumidores e produtores de biodiesel.

Segundo o MDA (2008), o semiárido brasileiro conta com quatro milhões de hectares aptos ao cultivo da mamona com cerca de 700 municípios potenciais produtores, que podem gerar um milhão de empregos, ajudando a complementar a renda dos pequenos agricultores e reduzindo a dependência de variações do preço da soja no mercado internacional.

A ricinocultura é a cultura de cultivo da mamona, explorada no Brasil em função do seu óleo extraído, que serve como matéria-prima para vários fins, como alimentação, química têxtil, papéis, plásticos, borrachas, perfumaria, cosméticos, farmácia, eletroeletrônicos, telecomunicações, tintas, adesivos, lubrificantes, etc. (BRASIL, 2017a). Trata-se, pois, de uma planta oleaginosa de relevante importância econômica e social. No Nordeste, a planta é encontrada abundantemente, concentrando cerca de $90 \%$ da produção nacional, de acordo com o IBGE (BRASIL, 2017b). De acordo com a mesma fonte, o Estado da Bahia responde por $90 \%$ da produção do Nordeste, onde a mamona apresenta ampla vantagem competitiva na produção, com reduzidos custos produtivos e ótima adaptação e resistência às secas, tornando-se alternativa viável para a produção e manejo.

Atualmente, as discussões a respeito de fontes alternativas de energia, sejam elas etanol, gás natural e biodiesel, vêm sendo reforçadas por questões de preocu- 
pação com o meio ambiente - o que acarreta em uma maior produção da mamona como alternativa redutora de emissões de gases $\mathrm{CO}_{2}$ e $\mathrm{SOx}$, respectivamente dióxido de carbono e óxido de enxofre, e aliado aos programas governamentais, fortalecendo a comercialização, promovendo maior empregabilidade e melhores alternativas para regiões subdesenvolvidas avançarem na região Nordeste do país, de acordo com Ferreira (2015).

No entanto, há algumas deficiências tecnológicas, oscilações no volume de produção em longo prazo promovendo variações político-econômicas, os baixos preços oferecidos aos produtores, a reduzida oferta de crédito, a desorganização dos sistemas de produção e do fluxo no mercado interno. É necessária uma percepção mais transparente e eficaz, bem como eficiente para minimizar riscos. Atores como bancos (crédito), produtores (investimentos) e o mercado (oferta e demanda) são imprescindíveis para atuarem como melhores ações de planejamento.

Com isso, o presente trabalho tem como objetivo apresentar um panorama acerca da produção da mamona nordestina entre os anos de 1990 a 2016. A produção será identificada pelo valor bruto de produção, verificando em que nível as componentes área colhida, produtividade média e preço influenciaram nas oscilações de crescimento. Tendo em vista que $90 \%$ da produção nordestina advêm da Bahia, os resultados a serem encontrados são extensivos a esse Estado, bem como podem se estender ao Brasil, visto que $90 \%$ da produção nacional advêm do Nordeste (BRASIL, 2010b). A revisão da literatura deste trabalho expõe as principais características acerca do mercado da mamona, compondo sob suas origens, relações com os programas de biodiesel e suas importâncias. Em seguida, são apresentados os materiais e métodos aplicados na pesquisa, com ênfase na discussão do Modelo Shift-Share, e os resultados são discutidos na sequência, detalhando-se o comportamento destas fases de produção, encerrando com as principais conclusões do estudo.

\section{REVISÃO DA LITERATURA}

\subsection{MAMONA E BIODIESEL}

Os biocombustíveis assumem características vantajosas ambientais, econômicas e sociais, e os seus processos de geração de energia são grandes referências na história, e o Brasil é reconhecido como líder na produção de biocombustíveis de 
origem vegetal. Em termos de políticas públicas, os planos governamentais incentivam a inserção de pequenos agricultores na cadeia produtiva deste setor, visando promover uma boa base de matérias-primas e o desenvolvimento e inclusão social dos pequenos agricultores, e segundo Santos (2015), os programas como um todo têm a diretriz de buscar a sustentabilidade da cadeia produtiva.

O biodiesel é uma opção brasileira ambiental e economicamente geradora de tecnologia, de divisas e de renda, segundo Farias et al. (2011). O Brasil é berço de grandes fontes de matérias, com especialidades em cada região. O Nordeste, por exemplo, caracteriza-se por grandes desafios em aspectos da seca e o clima como um todo, porém também excede vantagens na sua vegetação e diversidade de solo. As plantas oleaginosas são significantes para produção industrial do biodiesel e para o aspecto alimentício, dessa forma, segundo Melo (2016), avalia-se que o cultivo das matérias-primas participantes desta produção industrial eleva a empregabilidade além da variabilidade de fins.

Esta região do país impera com a produção da mamona e algodão. A mamona, com envoltos de grandes expectativas, também traduzia a redução da fome e miséria, por alguns anos dos governos federais, mas não foram atendidas como programado, apesar de mamona ter grande resistência à seca e ser de fácil adaptação aos solos. Diante disso, e com intervenção do Ministério do Desenvolvimento Agrário, embasou-se destas dificuldades e implantou-se melhores técnicas e projetos que visassem o melhor desempenho desta planta, incluindo outras na cadeia de produção.

A mamoneira pertence à família Euphorbiaceae, sendo atualmente cultivada em diversos países do mundo, destacando-se a Índia, a China e o Brasil, seu óleo é considerado um dos melhores para a produção de biodiesel, pela densidade, solubilidade em álcool e usos na química de mais de 700 produtos (BRITO et al., 2015).

Os óleos vegetais estão sendo estudados como alternativas para substituição progressiva dos combustíveis minerais derivados do petróleo, devido à redução da disponibilidade das fontes convencionais que promovem efeitos negativos ao meio ambiente. E a mamona conta com uma promissora inclusão social ao fomentar a agricultura familiar, principalmente na região Nordeste, fixando mão de obra e gerando empregos principalmente no semiárido, conforme Brito et al. (2015).

Visualiza-se também, em um contexto histórico, que na década de 70, a mamona, assim como outras fontes renováveis de energia, ganhou destaque na utilização como substituto dos derivados de petróleo como falado anteriormente, e novas descobertas desbravaram vantagens da mamona, como a produção de química têxtil, 
papéis, plásticos, cosméticos, farmácia, eletroeletrônicos, lubrificantes para aviões e naves espaciais, vidros e lentes, e outros similares.

O governo federal escolheu essa cultura como estratégica no contexto do PNPB, uma vez que apresenta baixo custo de implantação e produção, adequação às condições climáticas do semiárido em grande parte do território nordestino. Ademais, esses autores indicaram que a mamona é uma cultura de mão de obra intensiva, o que implica maior geração de renda dado o maior nível de emprego rural temporário, segundo Ferreira et al. (2015). Assim, considerando o fato de o Nordeste concentrar boa parte da pobreza rural no Brasil e ser uma área de clima semiárido, a mamona seria ideal para o cumprimento dos objetivos do PNPB.

Este Programa incentiva a produção e uso do biocombustível, buscando sustentabilidade da cadeia produtiva, além de garantir incentivos para os produtores que adquirem matérias-primas provenientes da agricultura familiar, promovendo a inserção social através da geração de renda (SANTOS, 2015). A principal importância do uso do biodiesel está relacionada à necessidade de redução da maior parte dos gases presentes nas emissões em decorrência do aquecimento global.

A mamoneira é uma planta pertencente à família das Euforbiáceas, a mesma da mandioca, da seringueira e do pinhão manso, e é originária provavelmente da África ou da Índia, sendo atualmente cultivada em diversos países do mundo, sendo a Índia, a China e o Brasil, nesta ordem, os maiores produtores mundiais (BRASIL, 2017a). O principal produto da mamoneira é seu óleo, o qual possui propriedades químicas peculiares que lhe fazem único na natureza: trata-se do ácido graxo ricinoleico que tem larga predominância na composição do óleo (cerca de 90\%) e possui uma hidroxila $(\mathrm{OH})$ o que lhe confere propriedades como alta viscosidade, estabilidade física e química e solubilidade em álcool a baixa temperatura.

A aplicação deste óleo é vasta, tanto em indústria química, quanto como matéria-prima promovendo diversas reações dando origem a produtos variados, desde lubrificantes a cosméticos e plásticos. Então, a escolha da mamona como fornecedora de matéria-prima para fabricação de biodiesel no Brasil pelo teor tecnológico adaptável no semiárido nordestino - sendo possível em outras regiões também - e na inclusão social de pequenos produtores que estavam sem opções agrícolas rentáveis, conforme aponta a Empresa Brasileira de Pesquisa Agropecuária (2017a). A 
mamona é uma planta heliófila, isto é, deve ser plantada exposta diretamente ao sol e não tolera sombreamento, tolerando ao estresse hídrico, todavia exigente em fertilidade do solo, pois embora seja forte à seca, seu contato com a água possibilita melhor produtividade.

O seu custo de produção varia bastante pelo fato de cada condição climática e nível tecnológico, bem como a cultura de plantio, manejo e colheita são influenciadores rigorosos sob o setor. Um dos principais compradores da mamona é a indústria de extração de óleo (que serve para produzir biodiesel ou para o mercado e ricinoquímica - óleo) (BRASIL, 2017a). E o seu preço de venda é influenciado pela produção mundial em aspectos da cotação do dólar, já que além do Brasil, a Índia e a China têm grandes indústrias e comercialização significativa.

Pela lógica economista, quando há períodos de déficit na produção e o preço tende a subir, por outro lado quando a produção é um pouco maior, o preço cai acentuadamente. Para diminuir esse risco, o governo federal, através do Conselho Nacional de Abastecimento - CONAB estipula um preço mínimo de comercialização para garantir ao menos os custos de produção do agricultor. Já que uma das políticas governamentais está sob o objetivo de incentivar os pequenos produtores.

De acordo com informações da EMBRAPA (Brasil, 2017a), a mamona é uma oleaginosa de destacada importância no Brasil e no mundo:

Seu óleo é uma matéria prima de aplicações únicas na indústria química devido a características peculiares de sua molécula que lhe fazem o único óleo vegetal naturalmente hidroxilado, além de uma composição com predominância de um único ácido graxo, ricinoléico, o qual lhe confere as propriedades químicas atípicas. Além da vasta aplicação na indústria química, a mamoneira é importante devido à sua tolerância à seca, tornando-se uma cultura viável para a região semi-árida do Brasil, onde há poucas alternativas agrícolas. No entanto, esta cultura não é exclusiva da região semi-árida, sendo também plantada com excelentes resultados em diversas regiões do país.

Seu cultivo comercial ocorre, praticamente, em todos os Estados da região Nordeste, que é responsável por $94 \%$ da área plantada com a cultura no país, e por 87\% da produção nacional em bagas. Segundo IBGE (2015b), a Bahia é o Estado que mais lidera a produção de mamona, sendo responsável por concentrar cerca de $80 \%$ da produção nacional. Vale salientar que a mamona representa um importante 
marco no aspecto socioeconômico no aspecto ligado à agricultura familiar, que utiliza a mão de obra da região e produz apenas em pequenas áreas, com carência na utilização de tecnologias avançadas e insumos modernos por parte dos agricultores.

O semiárido brasileiro conta com quatro milhões de hectares aptos ao cultivo da mamona com cerca de 700 municípios potenciais produtores que podem gerar um milhão de empregos, ajudando a complementar a renda dos pequenos agricultores e reduzindo a dependência de variações do preço da soja no mercado internacional, conforme o Ministério do Desenvolvimento Agrário (BRASIL, 2008c).

A maioria dos pequenos agricultores vive em condição de sobrevivência e o lado econômico é o principal fator de estímulo ao potencial cultivador de plantas oleaginosas como a mamona, que tem alto destaque como uma das culturas mais rentáveis do semiárido nordestino, sendo considerada a principal fonte de óleo para a produção de biodiesel no país. A importância das políticas é fator extremamente relevante para o desenvolvimento da produção de mamona no semiárido nordestino, principalmente para os pequenos agricultores, todavia carecem de melhores análises e estratégias para melhor desenvolvimento desta prática. As políticas públicas sofrem de estratégias mais adequadas, eficientes e eficazes para lidar com estes tipos de produção, o que acarreta em uma interdependência entre todos os agentes envolvidos.

A grande motivação para a produção do biodiesel no Nordeste está sob os aspectos econômicos, sociais e ambientais que esse combustível proporciona no tocante aos pequenos agricultores rurais, e o processo da mamona abraça um desenvolvimento sustentado em comunidades do semiárido pelo potencial de emprego e renda e inclusão, e esta produção integra uma alta adaptação às condições da região reduzindo a evasão do campo e consequentemente sua desestrutura e descontinuidade, de acordo com Silva e Lino (2008). Muito se justifica essas alternativas sustentáveis pela busca acadêmica, social e governamental diante da preocupação mundial com o ambiente e as desigualdades.

Alguns estudos ilustrados por Silva e Lino (2008) apontam que a grande adaptabilidade da mamona, estimada em 5 milhões de hectares, abrangendo 500 municípios, com apropriação tecnológica e logística, e profissionalização dos produtores com possibilidades de geração de 1 milhão de empregos nesse território com baixos custos aos governos, e sendo o biodiesel um importante produto para exportação e independência energética nacional, pois o Brasil se destaca por essa 
adaptação ao solo e clima. A mamona exige uma estação quente e úmida para favorecer a fase vegetativa e uma estação pouco chuvosa ou seca para permitir condições favoráveis ao cultivo e colheita.

\subsection{APLICAÇÕES DE MÉTODOS SOB O CONTEXTO DO SETOR DE BIOCOMBUS- TÍVEIS}

A partir das informações ofertadas no capítulo anterior deste setor e para a consolidação da pesquisa em questão, este estudo deparou-se com a necessidade de utilizar um modelo que trouxesse significados acerca dos dados envolvidos no setor da mamona no Nordeste do Brasil. Na literatura foi possível encontrar alguns trabalhos envolvendo questões similares e que o uso do Modelo Shift-Share adequaria à análise em questão, por ser um modelo matemático bastante utilizado, confiável, acessível e que possibilitaria extrair panoramas sobre os componentes da área colhida, produtividade média, e preço pago ao produtor, sob a taxa de crescimento do valor bruto da Produção da Mamona entre 1990 e 2016.

O Modelo Shift-Share, por exemplo, deu suporte à análise dos componentes da variação na quantidade produzida das principais lavouras da região Centro-Oeste entre 1975 e 1987 - período pelo qual a região participou consideravelmente na produção agrícola, conforme dissertaram Yokoyama e Igreja (1992). As oscilações nas taxas de crescimento eram respondidas pela associação aos efeitos de área, rendimento, localização e produção, gerando resultados que indicaram a modernização gradativa da agricultura, com foco nas lavouras exportáveis (a soja, como exemplo).

Os estudos levantados por Garcia e Buainain (2016) analisam a dinâmica de ocupação do cerrado nordestino entre 1990 a 2012, sob uma escala municipal, que permitiu perceber que a soja e o milho têm comandado a ocupação na fronteira agrícola, além de identificar e avaliar os componentes de variação do crescimento de uma região em relação ao seu espaço de referência. Este modelo também foi aplicado na decomposição da taxa de crescimento do valor da produção de cana-de-açúcar - nos efeitos área, rendimento e preço -, nos subefeitos escala e substituição, onde foi avaliada a expansão canavieira no Estado de São Paulo, por Câmara e Caldarelli (2016), verificando um período entre 1995 e 2013.

Além desses autores, Aguiar e Souza (2014) desenvolveram uma pesquisa que busca analisar o processo de substituição de culturas ocorrido nos principais 
produtores de cana-de-açúcar entre 2000 e 2010, sendo considerados os Estados que foram afetados pela expansão da área cultivada acrescentando a soja, favorecendo a inserção e crescimento de outros produtos.

Em outras áreas, o modelo encontra suas múltiplas funções e caracteriza eficientemente as pesquisas, como o exemplo de Gomes e Wander (2011), que avaliaram o crescimento das micro e pequenas empresas do setor comercial, industrial e de serviços em Palmas (TO) entre 2007 e 2009, com diagnóstico de evidenciar o crescimento entre portes empresariais e os setores com variáveis analisando a dinâmica de crescimento regional.

A facilidade de aplicação que revela as contribuições dos fatores comportamentais das variáveis estudadas aponta que mesmo com a simplicidade metodológica, não configura o modelo como inválido ou limitado, e a sua confiabilidade ultrapassa anos de estudo, onde é possível observar nas diferentes épocas que os trabalhos supracitados foram elaborados, outrossim, ao campo estudado, o modelo também se adequa e contempla satisfatoriamente o alcance das variações e dinâmicas comportamentais das variáveis envolvidas na pesquisa. A análise destas dinâmicas de produção através do Modelo Shift-Share é bastante utilizada e tem alcançado uma popularidade muito vasta, e a integração com os resultados permitem grandes subsídios para tomadas de decisões e formulações de políticas públicas.

\section{METODOLOGIA}

\subsection{ORIGEM DOS DADOS}

O valor bruto de produção (em $\mathrm{R} \$$ ) foi decomposto em três variáveis: área colhida pelo produtor de mamona em bagas, rendimento médio da produção (ou produtividade média) e preço pago ao produtor. A área colhida é medida em hectares; o rendimento médio da produção, que indica a produtividade do cultivo da mamona, é medido em quilogramas por hectare; e o preço pago ao produtor, em Reais por quilograma do produto, foi calculado dividindo-se a quantidade produzida pelo valor produzido. O período de análise estudado foram os anos de 1990 a 2016 . Na Tabela 1, observam-se os dados utilizados na análise, que tiveram origem na Pesquisa Agrícola Municipal dos anos de 1990 a 2016, realizados pelo IBGE (BRASIL, 2010a). 
Tabela 1. Origem dos dados para analisar a evolução do Valor Bruto de Produção da mamona: Nordeste, 1990-2016

\begin{tabular}{|c|c|c|c|c|}
\hline Ano & $\begin{array}{l}\text { Valor Bruto da } \\
\text { Produção (R\$) }\end{array}$ & $\begin{array}{c}\text { Área Colhida } \\
\text { (ha) }\end{array}$ & $\begin{array}{l}\text { Produtividade } \\
\text { Média (kg/ha) }\end{array}$ & Preço $(\mathrm{R} \$ / \mathbf{k g})$ \\
\hline 1990 & 700,96 & $267.581,00$ & 461,27 & 0,00001 \\
\hline 1991 & $4.542,88$ & $217.937,00$ & 511,29 & 0,00004 \\
\hline 1992 & $23.080,41$ & $164.872,00$ & 543,12 & 0,00026 \\
\hline 1993 & $288.935,64$ & $135.286,00$ & 264,62 & 0,00807 \\
\hline 1994 & $9.148 .000,00$ & $103.483,00$ & 487,28 & 0,18142 \\
\hline 1995 & $6.427 .000,00$ & $73.587,00$ & 401,12 & 0,21774 \\
\hline 1996 & $9.681 .000,00$ & $118.272,00$ & 334,04 & 0,24504 \\
\hline 1997 & $20.878 .000,00$ & $149.943,00$ & 625,40 & 0,22264 \\
\hline 1998 & $3.471 .000,00$ & $60.267,00$ & 218,11 & 0,26405 \\
\hline 1999 & $10.574 .000,00$ & $99.240,00$ & 283,23 & 0,37619 \\
\hline 2000 & $32.616 .000,00$ & $177.367,00$ & 492,57 & 0,37333 \\
\hline 2001 & $27.952 .000,00$ & $151.613,00$ & 483,92 & 0,38098 \\
\hline 2002 & $33.225 .000,00$ & $113.402,00$ & 590,96 & 0,49578 \\
\hline 2003 & $65.145 .000,00$ & $128.029,00$ & 591,03 & 0,86092 \\
\hline 2004 & $128.665 .000,00$ & $163.994,00$ & 772,36 & 1,01581 \\
\hline 2005 & $86.447 .000,00$ & $219.732,00$ & 700,94 & 0,56128 \\
\hline 2006 & $49.444 .000,00$ & $138.497,00$ & 601,31 & 0,59371 \\
\hline 2007 & $65.243 .000,00$ & $151.821,00$ & 552,10 & 0,77837 \\
\hline 2008 & $92.212 .000,00$ & $148.074,00$ & 731,60 & 0,85121 \\
\hline 2009 & $60.447 .000,00$ & $150.478,00$ & 523,00 & 0,28055 \\
\hline 2010 & $78.520 .000,00$ & $141.250,00$ & 589,00 & 0,94331 \\
\hline 2011 & $112.092 .000,00$ & $208.476,00$ & 576,00 & 0,93280 \\
\hline 2012 & $24.058 .000,00$ & $84.390,00$ & 308,00 & 0,92569 \\
\hline 2013 & $17.830 .000,00$ & $43.635,00$ & 287,00 & 1,42343 \\
\hline 2014 & $48.359 .000,00$ & $61.005,00$ & 576,00 & 1,37555 \\
\hline 2015 & $66.740 .000,00$ & $81.768,00$ & 565,00 & 1,44521 \\
\hline 2016 & $22.096 .000,00$ & $40.115,00$ & 551,00 & 0,55081 \\
\hline
\end{tabular}

Fonte: Elaboração própria, com base na Pesquisa Agrícola Municipal do IBGE (BRASIL, 2017a). 


\subsection{Modelo Shift-Share}

Para o presente estudo, optou-se pela utilização do modelo matemático Shift-Share, cujos resultados podem significar importantes indicadores para o planejamento dos atores envolvidos na produção da cultura da mamona. Neste contexto, tal modelo foi utilizado como uma adaptação para a decomposição da taxa de crescimento do valor da produção da mamona de 1990 a 2016 nas componentes área colhida, produtividade média e preço pago ao produtor, estimando-se a importância relativa de cada um dos componentes sobre seus comportamentos diante do Valor Bruto da Produção da mamona.

Conforme exposto neste trabalho, esse modelo tem sido utilizado em diversos campos do conhecimento manuseando diversas variáveis, destacando-se os trabalhos de Yokoyama e Igreja (1992), que analisaram a região Centro-Oeste em um corte regional e estadual, as atividades em área cultivada do arroz, feijão, milho e soja e o uso deste método ajudou a quantificar as fontes de crescimento. Outrossim, em uma análise mais anterior por Curtis (1972), ao verificar sob este modelo como técnica na pesquisa de desenvolvimento rural, nas dimensões de renda e emprego nos municípios rurais, embasou e impulsionou autores consolidando esta metodologia.

O modelo mede a situação entre dois extremos: o período inicial denominado "período zero" e o período final denominado "período t". Assim, no período inicial (0), o Valor Bruto da Produção $\left(V_{0}\right)$ é o produto da área colhida $\left(A_{0}\right)$, da produtividade ou rendimento médio $\left(R_{0}\right)$ e do preço pago ao produtor $\left(P_{0}\right)$, como proposto a seguir:

$$
V_{0}=A_{0} \cdot R_{0} \cdot P_{0}
$$

No período final $(t)$, por sua vez, o Valor Bruto da Produção $(V)$ é:

$$
V_{t}=A_{t} \cdot R_{t} \cdot P_{t}
$$

Como variáveis, define-se que: 
i) Vé o Valor Bruto da Produção da mamona (em Reais);

ii) A é a área colhida de mamona em bagas (em hectares);

iii) $R$ é o rendimento ou a produtividade média da mamona (em quilogramas por hectare);

iv) $P$ é o preço pago ao produtor da mamona (em Reais por quilograma).

Para se verificar os efeitos de cada um delas, serão isoladas, somente na área (no período $t$ ), permanecendo as demais componentes fixas no período zero. Nesse sentido, toma-se a variável $V^{A}$, em que:

$$
V_{t}^{A}=A_{t} \cdot R_{0} \cdot P_{0}
$$

Analogamente, a variável $V^{A, R}$ varia a área e o rendimento (produtividade), mantendo-se os preços constantes no período zero. Assim:

$$
V_{t}^{A, R}=A_{t} \cdot R_{t} \cdot P_{0}
$$

Importante verificar que a variação absoluta do Valor Bruto da Produção da mamona entre dois períodos $(t)$ e $(0)$ pode ser expressa da seguinte maneira:

$$
V_{t}-V_{0}=\left(A_{t} \cdot R_{t} \cdot P_{t}\right)-\left(A_{0} \cdot R_{0} \cdot P_{0}\right)
$$

A expressão acima pode ser escrita, eloquentemente, também desta forma:

$$
V_{t}-V_{0}=\left(V_{t}^{A}-V_{0}\right)+\left(V_{t}^{A, R}-V_{t}^{A}\right)+\left(V_{t}-V_{t}^{A, R}\right)
$$

Através da expressão (6), é possível perceber a desagregação dos efeitos da variação absoluta no Valor Bruto da Produção, isto é:

i) O termo $\left(V_{t}-V_{0}\right)$ diz respeito à variação total no Valor Bruto da Produção da mamona;

ii) O termo $\left(V_{t}^{A}-V_{0}\right)$ é o efeito-área, ou seja, a variação no Valor Bruto 
da Produção da mamona associada à variação de sua área colhida no mesmo horizonte de tempo;

iii) O termo $\left(V_{t}^{A, R}-V_{t}^{A}\right)$ é o efeito-rendimento, ou seja, a variação no Valor Bruto da Produção da mamona associada à variação de seu rendimento médio de cultivo (produtividade) no mesmo horizonte de tempo;

iv) O termo $\left(V_{t}-V_{t}^{A, R}\right)$ é o efeito-preço, ou seja, a variação no Valor Bruto da Produção da mamona associada à variação do preço pago ao produtor no mesmo horizonte de tempo.

Tais efeitos podem ser ainda apresentados em taxas anuais de crescimento (TAC). Para tanto, basta se utilizar da expressão (6) e dividir ambos os lados por ( $\left.V_{t}-V_{0}\right)$, ou seja:

$$
1=\frac{\left(V_{t}^{A}-V_{0}\right)}{V_{t}-V_{0}}+\frac{\left(V_{t}^{A, R}-V_{t}^{A}\right)}{V_{t}-V_{0}}+\frac{\left(V_{t}-V_{t}^{A, R}\right)}{V_{t}-V_{0}}
$$

Posteriormente, determina-se uma taxa de crescimento entre dois períodos, que no presente estudo será representada por uma taxa anual de crescimento do período (0) para o período $(t)$, em $\%$ :

$$
r=\left(\sqrt[t]{\frac{V_{t}}{V_{0}}}-1\right) \cdot 100
$$

Por fim, sendo $r$ a taxa anual de crescimento entre o período (0) e o período $(t)$, em valores percentuais, basta multiplicar ambos os lados da expressão (7) pela taxa $r$, encontrando-se assim os efeitos área, rendimento e preço em \%:

$$
r=\frac{\left(V_{t}^{A}-V_{0}\right)}{V_{t}-V_{0}} r+\frac{\left(V_{t}^{A, R}-V_{t}^{A}\right)}{V_{t}-V_{0}} r+\frac{\left(V_{t}-V_{t}^{A, R}\right)}{V_{t}-V_{0}} r
$$

Importante verificar que a multiplicação da taxa $r$ não altera os resultados obtidos pela expressão fundamental do Modelo Shift-Share, ou seja, a expressão (6). Nesse sentido, a expressão (9) nada mais traz do que os efeitos desagregados em \%.

No presente estudo, foram realizados dois tipos de análise sob o Modelo Shift-Share. Uma dinâmica verificação nas fontes de crescimento ou decréscimo do 
Valor Bruto da Produção da mamona em cada ano, entre 1990 e 2016. Por exemplo, deseja-se apontar qual a principal fonte do veemente crescimento entre os anos de 2003 e 2004, quando o Valor Bruto da Produção cresceu em 97,5\%. Por outro lado, também deseja-se verificar qual a principal fonte do forte decréscimo verificado entre os anos de 2005 e 2006, quando o Valor Bruto da Produção caiu cerca de 40\%, e também, por exemplo, entre 2011 e 2012 onde houve outro decréscimo significativo com restabelecimento suavemente crescente até 2015 . Dessa maneira, essa primeira análise traz resultados ano a ano. Nesse sentido, no Modelo Shift-Share descrito, considerou-se o ano $(t-1)$ como o período (0).

Por fim, uma última análise assume como período (0) aqueles anos em que ocorrem inícios de sequências de picos e vales no Valor Bruto da Produção da mamona, considerando-se os seguintes períodos de análise em cada fase descrita, em suma, o seu comportamento em blocos ao longo de tempos específicos em posição crescente: de 1990 a 1994, período em que ocorre forte acréscimo no Valor Bruto da Produção $\left(t_{0}=1990\right)$; de 1995, ano em que a produção cai com relação a 1994, até 1997, quando ocorre uma nova fase de acréscimos $\left(t_{0}=1995\right)$; de 1998, ano em que se verifica queda com relação a 1997, até 2000, quando a mamona experimenta nova fase de expansão no seu Valor Bruto da Produção $\left(t_{0}=1998\right)$; de 2001, quando se verifica leve queda com relação a 2000, até o ano de 2004, período em que se verifica amplo crescimento $\left(t_{0}=2000\right)$; de 2004 a 2006, período em que se verifica forte queda $\left(t_{0}=2004\right)$; de 2006 até 2008, período em que o Valor Bruto da Produção volta a se elevar $\left(t_{0}=2006\right)$; de 2008 a 2012, período em que se verifica um crescimento crescente, e uma significativa queda entre o ano 2011 e $2012\left(\mathrm{t}_{0}=\right.$ 2008); de 2012 até 2016, período em que se verifica um aumento suave desde o $\mathrm{t}_{0}=$ 2012 até 2015 , sofrendo em 2016 um declínio.

\section{RESULTADOS E DISCUSSÃO}

É compreendido que entre os anos de 1990 e 2016 houve oscilações no Valor Bruto da Produção da mamona. A Figura 1 aponta valores menores nos primeiros anos de estudo na pesquisa, até 1993, logo após o advento do Plano Real, propor- 
cionando melhor desenvolvimento das práticas agrícolas, notou-se um aumento no preço pago ao produtor de mamona. A explosão dos preços se verifica até o ano de 2004, quando foi implantado o ProBiodiesel do Governo Federal, que acarretou em uma elevação da demanda superior à oferta até então observada, implicando na brusca queda dos preços entre os anos de 2004 e 2005. Nos anos seguintes, os preços das produções retornaram ao pico, em consonância com o ajuste de oferta. Em 2016, contempla um declínio significante no preço, decorrente da crise - ocasionando falta de incentivos financeiros e inexistência de um preço mínimo para a comercialização no mercado nacional - e de condições climáticas adversas.

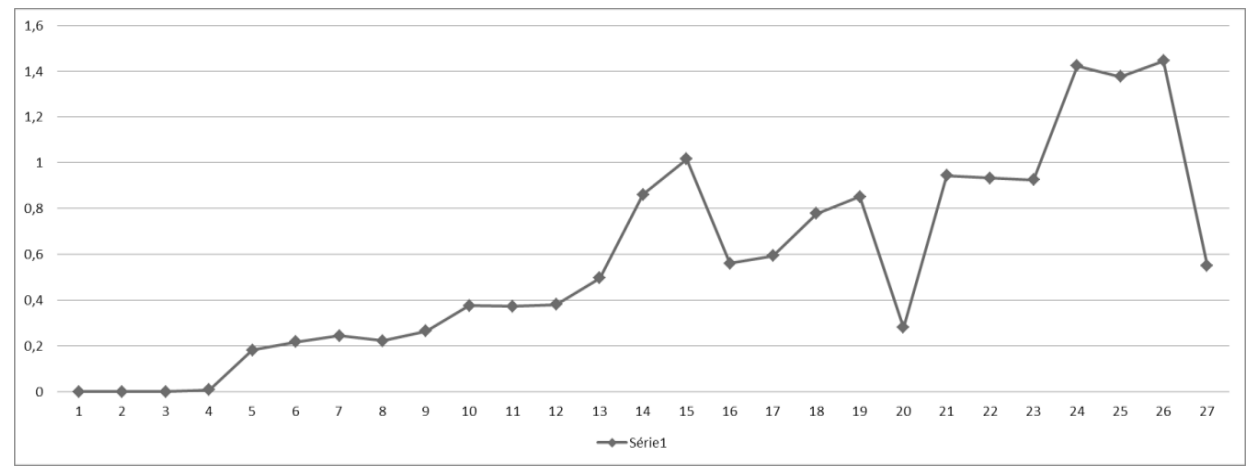

Figura 1. Evolução do preço pago ao produtor de mamona: Nordeste, 1990-2016 (R\$/kg). Fonte: Pesquisa Agrícola Municipal do IBGE (BRASIL, 2010a).

Em termos de área colhida e quantidade produzida de mamona, constata-se uma movimentação caracterizada por significativas oscilações, conforme apresentado nas Figuras 2 e 3. Alguns fatores refletem na instabilidade da produção, como variações climáticas, pragas e doenças, acompanhadas de quedas no preço de um ano para o outro. 


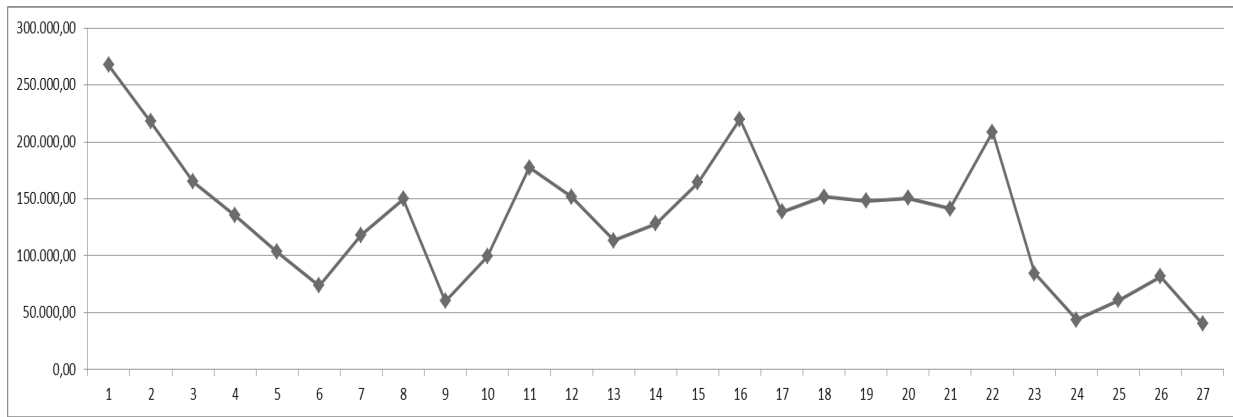

Figura 2. Evolução da área colhida de mamona: Nordeste, 1990-2016 (ha).

Fonte: Pesquisa Agrícola Municipal do IBGE (BRASIL, 2010a).

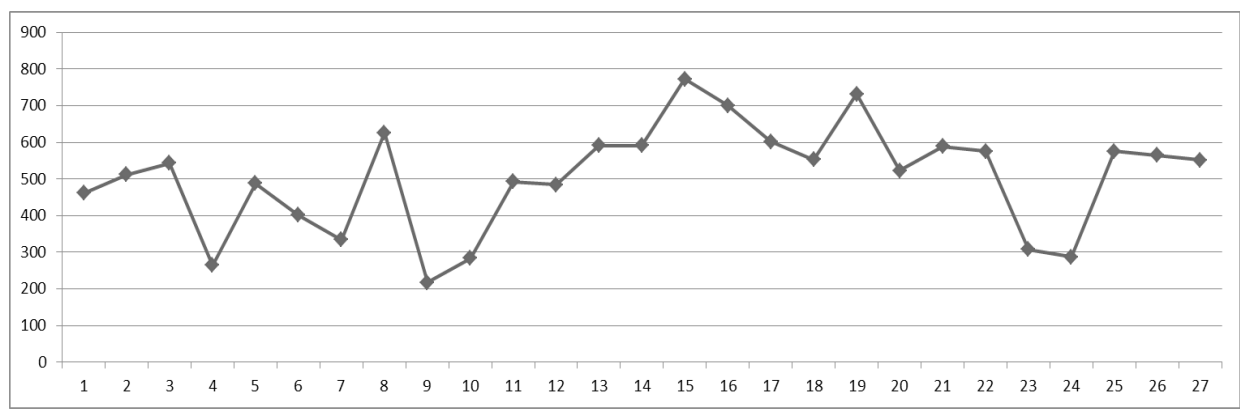

Figura 3. Evolução da quantidade produzida de mamona: Nordeste, 1990-2016 (ton).

Fonte: Pesquisa Agrícola Municipal do IBGE (BRASIL, 2010a).

Ao verificar as oscilações, observa-se uma inclinação decrescente na área colhida, tendenciando o crescimento da produtividade, e conforme a Figura 4 houve um comportamento ascendente ao longo do período analisado, portanto, os órgãos devem ofertar capacidades para atender os produtores incentivando no aspecto tecnológico. 


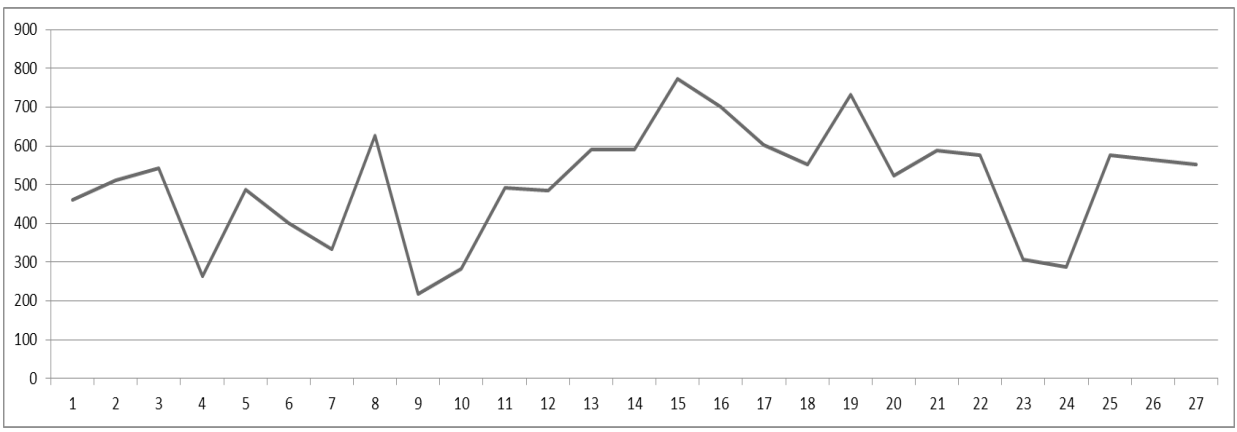

Figura 4. Produtividade ou rendimento médio na produção de mamona: Nordeste, 1990-2016 (kg/ha). Fonte: Pesquisa Agrícola Municipal do IBGE (BRASIL, 2010a).

Verifica-se na figura abaixo o comportamento apresentado pelo Valor Bruto da Produção da mamona, calculado como o produto entre a área colhida, a produtividade média e o preço pago ao produtor. Nesse aspecto, observam-se valores reduzidos entre 1990 e 1993, com aumento significativo a partir de 1994, em consequência dos desdobramentos do Plano Real. O alongamento de dívidas dos agricultores, com o Programa de Revitalização de Cooperativas de Produção Agropecuária (RECOOP), que refinancia as dívidas e financia o capital de giro e investimentos foram considerados peças-chave para o significativo crescimento.

Entretanto, no período entre 2004 e 2006, verificou-se queda acentuada no Valor Bruto da Produção, o que deve estar associado à queda em cerca de $40 \%$ nos preços pagos aos produtores, concomitantemente a uma redução na produtividade. Contudo, nos últimos anos da série estudada, o Valor Bruto da Produção da mamona voltou a subir, o que pode ser atribuído ao aumento simultâneo na área colhida, na produtividade e nos preços pagos ao produtor.

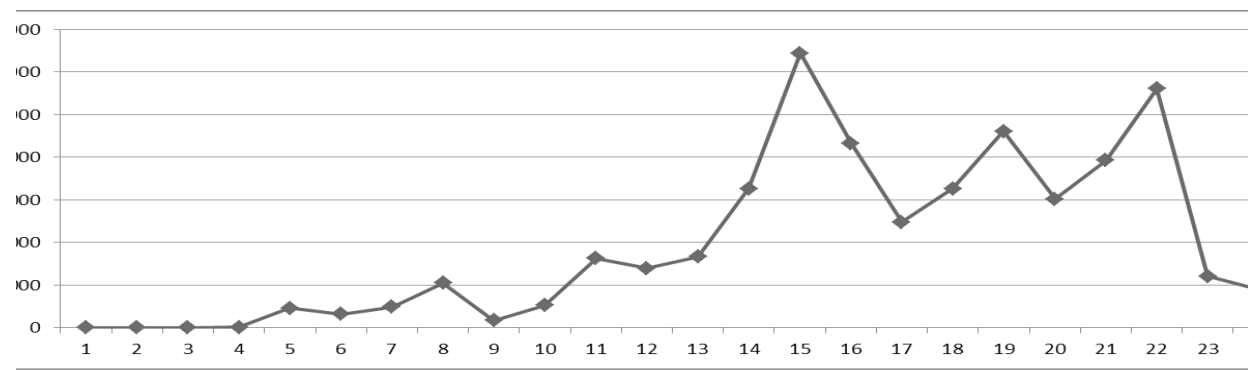

Figura 5. Evolução do Valor Bruto da Produção da mamona: Nordeste, 1990-2016 (R\$1.000). Fonte: Pesquisa Agrícola Municipal do IBGE (BRASIL, 2010a). 
Ao perceber as variações da produção da mamona, a primeira aplicação do Modelo Shift-Share foi feita sobre variações entre o período $(t)$ e o período $(t-1)$. Nesse sentido, foi possível obter as fontes de variação do Valor Bruto da Produção da mamona a cada ano, conforme descrito na Tabela 2.

Tabela 2. Fontes de crescimento do Valor Bruto da Produção de mamona: Nordeste, 19902016 (ano base: $t-1$ ).

\begin{tabular}{|c|c|c|c|c|}
\hline Ano & $\begin{array}{c}\text { Efeito-Total } \\
\text { (\% a.a.) }\end{array}$ & $\begin{array}{c}\text { Efeito-Área } \\
\text { (\%a.a.) }\end{array}$ & $\begin{array}{l}\text { Efeito-Produti- } \\
\text { vidade (\%a.a.) }\end{array}$ & $\begin{array}{c}\text { Efeito-Preço } \\
\text { (\%a.a.) }\end{array}$ \\
\hline 1990 & - & - & - & - \\
\hline 1991 & 548,09 & $-18,55$ & 8,83 & 557,81 \\
\hline 1992 & 408,06 & $-24,35$ & 4,71 & 427,70 \\
\hline 1993 & $1.151,87$ & $-17,94$ & $-42,08$ & $1.211,89$ \\
\hline 1994 & $3.066,10$ & $-23,51$ & 64,36 & $3.025,25$ \\
\hline 1995 & $-29,74$ & $-28,89$ & $-12,57$ & 11,72 \\
\hline 1996 & 50,63 & 60,72 & $-26,88$ & 16,78 \\
\hline 1997 & 115,66 & 26,78 & 110,58 & $-21,70$ \\
\hline 1998 & $-83,37$ & $-59,81$ & $-26,18$ & 2,61 \\
\hline 1999 & 204,64 & 64,67 & 49,16 & 90,81 \\
\hline 2000 & 208,45 & 78,73 & 132,10 & $-2,37$ \\
\hline 2001 & $-14,30$ & $-14,52$ & $-1,50$ & 1,72 \\
\hline 2002 & 18,86 & $-25,20$ & 16,55 & 27,52 \\
\hline 2003 & 96,07 & 12,90 & 0,01 & 83,16 \\
\hline 2004 & 97,51 & 28,09 & 39,30 & 30,12 \\
\hline 2005 & $-32,81$ & 33,99 & $-12,39$ & $-54,41$ \\
\hline 2006 & $-42,80$ & $-36,97$ & $-8,96$ & 3,12 \\
\hline 2007 & 31,95 & 9,62 & $-8,97$ & 31,30 \\
\hline 2008 & 41,34 & $-2,47$ & 31,71 & 12,09 \\
\hline 2009 & 62,98 & $-0,015$ & 0,00025 & 63 \\
\hline 2010 & 69,33 & $-0,0005$ & 0,0002 & 69,33 \\
\hline 2011 & 68,02 & $-0,00165$ & 0,000145 & 68,018 \\
\hline 2012 & 53,647 & $-0,0019$ & $-0,00029$ & 53,65 \\
\hline 2013 & 49,04 & $-0,003$ & $-0,0002$ & 49,048 \\
\hline 2014 & 52,655 & $-0,001$ & 0,00008 & 52,656 \\
\hline 2015 & 4,53 & $-0,000058$ & 0,0000057 & 4,5 \\
\hline 2016 & 40,58 & $-0,0035$ & 0,0001 & 40,584 \\
\hline
\end{tabular}

Fonte: Elaboração própria. 
Nesse sentido, algumas características da evolução do VBP podem ser destacadas, uma delas é o crescimento nos primeiros anos da série, explicado pelo preço pago ao produtor neste período, sendo essa a principal fonte de acréscimo. Em contrapartida, o efeito-área se mostrou sempre negativo, enquanto o efeito-produtividade sofreu oscilações. Em 1995, por sua vez, verificou-se a primeira queda no valor da produção da mamona, resultante principalmente do efeito-área negativo e, em menor grau, do efeito-produtividade também negativo. Apesar do efeito-preço ter se mostrado positivo, este não foi capaz de superar as demais variáveis contornando o resultado.

Outros anos foram caracterizados por queda no VBP da mamona com relação ao ano anterior: em 1998, fortemente influenciado pelo efeito-área e, em menor grau, pelo efeito-produtividade; em 2001, influenciado predominantemente pelo efeito-área; em 2005, pelo efeito-preço e, em menor grau, pelo efeito-produtividade; e em 2006, pelo efeito-área e, em menor grau, pelo efeito-produtividade.

Além de 1994, por sua vez, os principais picos com relação ao ano anterior foram percebidos também em 1997, influenciado pelo efeito-produtividade e levemente pelo efeito-área; em 1999, explicado pelo efeito-preço e, em menor grau, pelo efeito-área e pelo efeito-produtividade; em 2000, explicado principalmente pelo efeito-área e pelo efeito-produtividade; em 2003, devido ao efeito-preço e, em menor escala, pelo efeito-área; e em 2004, com participações semelhantes de todas as componentes. Em 2008, verificou-se que o crescimento do valor da produção relativo ao ano anterior, que deveu-se pela contribuição do efeito-produtividade, e de uma parte do efeito-preço, mesmo com consequências negativas leves oriundas do efeito-área. Nos anos seguintes o VBP oscilou menos vezes, com grande divergência no preço em 2015. A partir de 2006 até o último ano da série tiveram momentos negativos no efeito-área, devendo-se pela diminuição da produtividade, e de forma suave pelo decréscimo leve do preço.

A Tabela 3 traz a participação das componentes área, produtividade e preço sobre fases distintas na série estudada, tendo os cálculos levados em consideração sob o primeiro ano de cada período como ano base. As taxas percentuais encontradas dizem respeito, portanto, à variação anual média entre o ano final e o inicial formando blocos de análise, sendo possível a visualização montada da mesma forma das tabelas iniciais desta pesquisa. 
Tabela 3. Fontes de crescimento do Valor Bruto da Produção de mamona: Nordeste, fases distintas de 1990-2016

\begin{tabular}{c|c|c|c|c}
\hline Período & $\begin{array}{c}\text { Efeito-Total } \\
\text { (\% a.a.) }\end{array}$ & $\begin{array}{c}\text { Efeito-Área } \\
\text { (\%a.a.) }\end{array}$ & $\begin{array}{c}\text { Efeito-Produtivida- } \\
\text { de (\%a.a.) }\end{array}$ & $\begin{array}{c}\text { Efeito-Preço } \\
\text { (\%a.a.) }\end{array}$ \\
\hline 1990-1994 (base: 1990 ) & 968,83 & $-0,05$ & 0,00 & 968,87 \\
\hline 1995-1997 (base: 1995 ) & 80,24 & 37,03 & 40,66 & 2,55 \\
\hline 1998-2000 (base: 1998 ) & 206,54 & 47,79 & 91,09 & 67,65 \\
\hline 2001-2004 (base: 2001 ) & 66,35 & 1,50 & 11,87 & 52,97 \\
\hline 2004-2006 (base: 2004 ) & $-38,01$ & $-9,60$ & $-11,55$ & $-16,87$ \\
\hline 2006-2008 (base: 2006 ) & 36,56 & 2,92 & 9,79 & 23,85 \\
\hline 2008-2012 (base: 2008 ) & $-24,9$ & $-13,7$ & $-10,5$ & $-0,67$ \\
\hline 2012-2016 (base: 2012) & $-137,68$ & $-16,63$ & $-11,88$ & $-109,16$ \\
\hline
\end{tabular}

Fonte: Elaboração própria.

O efeito-preço está intimamente ligado à ascensão no Valor Bruto da Produção da mamona correspondente ao período 1990-94. Entre 1995 e 1997, por sua vez, o crescimento se mostrou menos impactante, tendo como principais fontes o efeito-produtividade e o efeito-área. Um novo período de forte ascensão foi observado entre 1998 e 2000 , dessa vez influenciado por todas as componentes, tendo mais potencial no efeito-produtividade. O ritmo desacelerou entre 2001 e 2004, período em que o efeito-preço se demonstrou mais importante dentre as demais componentes. Por sua vez, o único período de decréscimo consecutivo se deu entre 2004 e 2006, respondendo a variações negativas de todos os efeitos em escalas semelhantes. Observa-se que, considerando a análise por fases distintas, o efeito-preço se destaca como principal fonte das variações do Valor Bruto da Produção da mamona, entre os anos de 1990 e 1998. Como verificado, sua contribuição se mostrou mais elevada em todos os períodos considerados, exceto nas fases de 1995 a 1997, quando teve ínfima participação; e entre 1998 e 2000, quando seu efeito só se mostrou inferior ao efeito-produtividade. Os períodos de 2008 a 2016 mostraram-se sempre em redução em relação aos períodos isolados anteriormente, sofrendo grande influência do efeito-preço. Percebe-se que os últimos períodos analisados sofrem oscilações decorrentes de possíveis abalos na estrutura política e econômica dos produtos comercializados devido à crise que assolou o país em diversos momentos desestruturando continuidade de políticas públicas dos governos e/ou reformas, em 
paralelo com situações de crise natural, com os abalos climáticos.

\section{CONCLUSÕES}

Conforme dados divulgados pela Companhia Nacional de Abastecimento (CONAB) a estimativa de área plantada para a safra de 2017 é de 31,8 safras, sofrendo um aumento de 5,3\% com relação a 2016. Assim como a produtividade tende a ser superior ao ano anterior, tendo sempre como líder nordestino o Estado da Bahia, na produção da mamona, respondendo grande parte desta variação, uma vez que as fontes de crescimento do VBP da mamona advêm da região nordestina em $90 \%$ em relação ao país.

No período em análise, picos e vales puderam tomar alguns pontos dos gráficos apresentados sobre o comportamento da produção de mamona no Nordeste. Em 2004, identificado como o maior índice rendeu o valor da produção em $\mathrm{R} \$ 128,7$ milhões, resultado associado à implantação do Programa de Biodiesel do governo federal. Já em 2008, o valor da produção alcançou R\$92,2 milhões, correspondente à produção de 108,3 mil toneladas de mamona em bagas. A produção é quase que exclusivamente voltada ao mercado nacional, e em 2011 a produção atinge significativamente outro pico de $\mathrm{R} \$ 112$ milhões.

Quanto à aplicação do Modelo Shift-Share, as seguintes conclusões podem ser elaboradas: entre 1990 e 1994, o efeito-preço foi responsável pelo significativo pico de crescimento no valor da produção neste período; em 1995, houve uma queda com relação a 1994, resultante principalmente pelo efeito-área; entre 1995 e 1997, a nova fase de crescimento se deu em função do efeito-produtividade e do efeito-área; em 1998, uma nova queda foi verificada com relação ao ano anterior, devido principalmente ao efeito-produtividade; entre 1998 e 2000, o crescimento retomou os picos baseado na influência do efeito-produtividade, ainda que as demais componentes também tenham contribuições consideravelmente positivas; em 2001, o valor da produção novamente caiu com relação ao ano anterior, principalmente devido ao efeito-área; entre 2001 e 2004, o crescimento no valor da produção foi influenciado pelo efeito-preço; entre 2004 e 2006, deu-se a única fase de anos conse- 
cutivos com decréscimo no valor da produção, com influências de efeitos negativos em todas as componentes; entre 2006 e 2008, verificou-se nova fase de crescimento, associada principalmente ao efeito-preço; em 2011, oscilações crescentes oriundas do efeito-área e em 2016 pelo efeito-preço influenciando na produção de forma reduzida.

Vale salientar que o efeito-área se relaciona fortemente com a área-colhida, e o efeito-produtividade tem forte ligação com a rotatividade de culturas, que em seu mau uso causa a depreciação do solo. Por sua vez, ratifica-se a necessidade de implantação de novas tecnologias propiciando uma melhoria na qualidade do produto. Os créditos disponíveis e os incentivos fortalecem o valor de produção e a comercialização, e o relacionamento entre os produtores da matéria-prima e os empresários da indústria é essencial, assim como o comprometimento governamental, no sentido de aplicar políticas adequadas, tendo em vista a importância socioeconômica do setor.

\section{REFERÊNCIAS}

AGUIAR, C. J.; SOUZA, P. M. de. Impactos do crescimento da produção de cana-de-açúcar na agricultura dos oito maiores estados produtores. Revista Economia e Extensão Rural. 2014.

BRASIL, Empresa Brasileira de Pesquisa Agropecuária. Portal de informações sobre a mamona. Disponível em: http://www.cnpa.embrapa.br/produtos/mamona/ index.html. Acesso em: maio 2017a.

BRASIL, Ministério do Desenvolvimento Agrário. www.mda.gov.br. Acesso em maio 2017 c.

BRITO, K. Q. D.; SOUZA, F. G. de; JUNIOR, G. J. D.; BRITO, K. S. A. Efeito da salinidade na germinação e desenvolvimento inicial da mamona "BRS energia". Revista Verde, v. 10, n. 04, p. 17-20, out-dez, 2015. 
CAMARA, M. R. G. da; CALDARELLI, C. E. Expansão canavieira e o uso da terra no estado de São Paulo. Revista Dilemas ambientais e fronteiras do conhecimento, São Paulo, 2016.

CONAB - Companhia Nacional de Abastecimento. www.conab.gov.br. Acesso em: maio, 2017.

CURTIS, W. C. Shift-Share Analysis as a Technique in Rural Development Research, American Journal of Agricultural Economics, AAEA, 1972.

FARIAS, A. C. M. de.; SANTANA, J. S. de.; FILHO, M. F. Oliveira; BARBOSA, C. R. F.; MEDEIROS, J. T. N. Os combustíveis verdes do Brasil - avaliação da lubricidade do biodiesel B5 e óleos de mamona e coco. Revista Holos, 2011.

FERREIRA, M. D. P.; DANIEL, L. P.; LIMA, J. E. de. O Programa Brasileiro de Biodiesel e o Risco Associado ao Preço da Mamona em Irecê, Bahia, Revista de Economia e Sociologia Rural, 2015.

GARCIA, J. R.; BUAINAIN, A. M. Dinâmica de ocupação do Cerrado Nordestino pela Agricultura: 1990 e 2012. DOI: 10.590/1234.56781806-947900540207, 2016.

GOMES, D. H.; WANDER, A. E. Análise do crescimento das micro e pequenas empresas de Palmas-TO. 2011.

IBGE, Instituto Brasileiro de Geografia e Estatística. www.ibge.gov.br. Acesso em: maio $2017 \mathrm{~b}$.

MELO, C. D. de. Potencialidade do Nordeste para o Setor de Biocombustível: Revisão Bibliográfica. UFRN, Natal, 2016.

SANTOS, L. K. dos; CALERA, G. C.; STRINGACI, J. C. T.; VILAÇA, S. M.; VIVIANI, V. E.; FLUMINGAN, D. L. Estado da arte da aplicação do processo de hidroesterificação 
na produção de biodiesel a partir de matérias-primas de baixa qualidade. Revista Principia/IFPB, 28. ed. João Pessoa. Dez. 2015.

SILVA, N. G. A.; LINO, A. de S. Mamona e biodiesel: oportunidade para o semi-árido. Grupo de pesquisa: agricultura, meio ambiente e desenvolvimento sustentável. SOBER Regional, Rio Branco, Acre, Jul, 2008.

YOKOYAMA, L.P.; IGREJA, A. C. M. Principais lavouras da região centro-oeste: variações no período 1975-1987. Revista Pesquisa Agropecuária Brasileira, v. 27, n. 5, p. 727-736. Brasília: EMBRAPA, 1992.

Recebido em: 19/07/2017 Aceito em: 24/05/2018 